\title{
Intraoperative Image-Guided Breast-Conservation Surgery Should be the Gold Standard
}

\author{
V. Suzanne Klimberg, MD \\ Division of Breast Surgical Oncology, Department of Surgery and Pathology, University of Arkansas for Medical Sciences \\ (UAMS), Winthrop P. Rockefeller Cancer Institute, Little Rock, AR
}

The COBALT trial ${ }^{1}$ is a small randomized multicenter trial (134 patients) for unicentric palpable breast cancers conducted in the Netherlands primarily to demonstrate the superiority of intraoperative ultrasound (US)-guided breastconservation surgery (BCS) in terms of both cosmesis and patient satisfaction. Indeed, the cosmesis was better for the image-guided surgery than for the palpation-guided surgery, as judged by a three-member panel, a computer program, and self-evaluation (odds ratio, $0.55 ; p=0.067$ ). This was primarily due to less volume of excision with US-guided BCS, less reexcision due to positive margins, and improved patient satisfaction. This ultimately led to lower cost, although this datum is not presented in the report. Likewise, Rubio et al. ${ }^{2}$ demonstrated utility in the neoadjuvant setting using a USVisible marker placed at the original biopsy.

\section{IMPLEMENTATION IN CLINICAL PRACTICE}

As described in both reports, the study results would not be difficult to implement in a busy clinical practice. A variety of ultrasound machines are currently available in most operating rooms that could be used for US-guided surgery. This is how I started in my practice more than 20 years ago. I did not charge for such procedures because they were part of my learning curve and because at that time, no certification for surgeons or US courses were available. It made sense that any image-guided procedure was better than what I could feel with my hands.

(C) Society of Surgical Oncology 2015

First Received: 25 September 2015; Published Online: 17 November 2015

V. S. Klimberg, MD

e-mail: klimbergsuzanne@uams.edu
One thing that received no comment in the reports was the use of ex vivo US confirmation of excision completeness immediately on the operating table that could then direct reexcision of a specific margin. How many times has each of us removed a mass only to find that it was not in the center of the lumpectomy specimen. Ultrasound both in vivo and ex vivo help to direct and redirect our efforts, respectively.

\section{FURTHER USE OF IMAGE-GUIDED US IN BOTH THE OPERATING ROOM AND THE CLINIC}

The two studies demonstrate the most rudimentary of uses for surgical US. As proficiency with US is gained by the surgeon, primary lesions and those demonstrated only by US can be removed with the same level of confidence. Many articles attest to the ability to do so. ${ }^{3}$

The obvious benefit for the patient is that he or she does not need to undergo a secondary localization procedure. ${ }^{4}$ We and others have demonstrated the usefulness of intraoperative US after a positive stereotactic core biopsy that results in the need for BCS therapy. The patients traditionally require needle localization breast biopsy (NLBB), a most barbaric procedure during which $10-20 \%$ of patients faint or vomit due to vasovagal reflex. ${ }^{5}$

Many procedures have used clips, coils, cryoablation, and radioactive seeds as second procedures to locate nonpalpable lesions, all with results similar to those for NLBB. ${ }^{6}$ Our group has demonstrated the usefulness of using the hematoma created in almost all patients after a core biopsy that lasts up to 5 weeks for most patients. We termed this the hematoma-directed ultrasound-guided (HUG) procedure. $^{4}$

Arentz et al. ${ }^{7}$ demonstrated better margin clearance than with traditional NLBB. In addition, a recent study 
demonstrated that if the US-imaged margin is at least $1 \mathrm{~cm}$, the patient is highly unlikely to have a positive margin. ${ }^{8}$ If the lesion or hematoma is not visible, then use of USvisible clips, as applied by Rubio et al., can be very useful, especially in the neoadjuvant setting. ${ }^{9}$ One can readily see the direct correlation with patient satisfaction and with facilitation of the surgeon's scheduling of operating rooms.

Beyond the operating room, many uses facilitate both patient care and cost savings in the clinic. Ultrasoundguided core biopsy facilitates the diagnosis of benign and cancerous breast masses as well as lymph node evaluation and biopsy. Henry-Tillman et al. ${ }^{10}$ demonstrated a huge cost savings with core biopsy of axillary lymph nodes used to evaluate patients for neoadjuvant chemotherapy.

\section{SURGICAL STANDARDS FOR US PERFORMANCE BY SURGEONS}

How then do clinicians become proficient at imageguided core and open biopsy? The first recommendation is to take one of the many courses offered by the American College of Surgeons (ACS) or the American Society of Breast Surgeons (ASBrS). Both basic and more advanced courses are offered at the time of the regular meetings. Next, I suggest reviewing and starting to comply with the standards set forth by the ASBrS for US and US-guided biopsy. ${ }^{11}$ To qualify for certification, the surgeon is required to be board certified; to have a documented appropriate level of training and a minimum of 1-year experience in the performance and interpretation of breast US; to pass a written exam given by the ASBrS several times a year; to manage at least 100 cases of diagnostic US (per year); to review a minimum of 100 mammography exams annually as well as 80 diagnostic and 20 interventional procedures per year; to perform systematic review and evaluation of interpretation, complications, and adverse events, with submission of at least 5 diagnostic and 5 interventional cases for review; to acquire 15 category 1 CME credits in breast US per year; and to undergo reaccreditation every 5 years. ${ }^{10}$

Ultrasound certification may seem daunting, adding to a long list of arduous requirements for the busy breast or general surgeon who does a significant amount of breast surgery. However, I suggest that surgeons start at the beginning with palpable lesions using an approach similar to that in the COBALT trial and realize the benefits both to their practice and to patient outcomes and satisfaction.

ACKNOWLEDGMENTS This study was supported by the Fashion Footwear Association of New York (FFANY/QVC).

DISCLOSURE Medical Director for Ascendant Diagnostics, Inc.

\section{REFERENCES}

1. Haloua MH, Volders JH, Krekel NMA, Lopes Cardozo AMF, de Roos WK, de Widt-Levert LM, et al. Intraoperative ultrasound guidance in breast-conserving surgery improves cosmetic outcomes and patient satisfaction: results of a multicenter randomized controlled trial (COBALT). Ann Surg Oncol. 2015. doi:10.1245/s10434-015-4906-4.

2. Rubio IT, Esgueva-Colmenarejo A, Espinosa-Bravo M, Salazar JP, Miranda I, Peg V. Intraoperative ultrasound-guided lumpectomy versus mammographic wire localization for breast cancer patients after neoadjuvant treatment. Ann Surg Oncol. 2015. doi:10.1245/s10434-015-4935-z.

3. Thompson M, Klimberg VS. Use of ultrasound in breast surgery. Surg Clin North Am. 2007;87:469-84.

4. Thompson M, Henry-Tillman R, Margulies A, Thostenson J, Bryant-Smith G, Fincher R, Korourian S, Klimberg VS. Hematoma-directed ultrasound-guided (HUG) breast lumpectomy. Ann Surg Oncol. 2007;14:148-56.

5. Kelly P, Winslow EH. Needle wire localization for nonpalpable breast lesions: sensations, anxiety levels, and informational needs. Oncol Nurs Forum. 1996;23:639-45.

6. Tomkovich KR. Interventional radiology in the diagnosis and treatment of diseases of the breast: a historical review and future perspective based on currently available techniques. Am J Roentgenol. 2014;203:725-33.

7. Arentz C, Baxter K, Boneti C, Henry-Tillman R, Westbrook K, Korourian S, Klimberg VS. Ten-year experience with hematomadirected ultrasound-guided (HUG) breast lumpectomy. Ann Surg Oncol. 2010;17(Suppl 3):378-83.

8. Ouldamer L, Lechaux E, Arbion F, Body G, Vildé A. What should be the width of radiological margin to optimize resection of nonpalpable invasive or in situ ductal carcinoma? Breast. 2014;23:889-93.

9. Corsi F, Sorrentino L, Sartani A, Bossi D, Amadori R, Nebuloni M, Truffi M, Bonzini M, Foschi D. Localization of nonpalpable breast lesions with sonographically visible clip: optimizing tailored resection and clear margins. Am J Surg. 2015;209:950-8.

10. Henry-Tillman R, Glover-Collins K, Preston M, Gallagher K, Tummel E, Robertson YV, Ochoa D, Korourian S, Westbrook K, Klimberg VS. The SAVE review: sonographic analysis versus excision for axillary staging in breast cancer. J Am Coll Surg. 2015;220:560-7.

11. https://www.breastsurgeons.org/certification/breast_ultrasound_ certification.php. 